\title{
An analysis of the social background of minority ethnic applicants to medicine and dentistry
}

\author{
Social background of minority ethnic applicants to medicine and dentistry by R. Bedi and M. S. Gilthorpe \\ Br Dent J 2000; 189: 152-154
}

\section{Aim}

To explore ethnic variations in social background of successful applicants to undergraduate United Kingdom medical and dental schools.

\section{Method}

Retrospective analyses of University and College Admissions Services data on all students to commence study in pre-clinical medicine and dentistry, during the academic years 1994/5, 1995/6 and 1996/7. Analyses were undertaken for two categories of social class, namely higher (professional and intermediate) and lower (skilled non-manual, skilled manual, partly skilled, and unskilled) social class.

\section{Results}

Over 15 thousand students were accepted to study medicine and dentistry during the three-year study period, of which $80 \%$ were from high social class backgrounds. More medical (80.9\%) students were from high social class backgrounds than dental (73.3\%) students $(\mathrm{OR}=1.54,95 \% \mathrm{CI}=1.39,1.70)$. Social class differences were observed, with a greater proportion of higher social class students amongst the white students than amongst the minority ethnic students $(\mathrm{OR}=1.42,95 \% \mathrm{CI}=1.30,1.55)$. This was more marked in dentistry $(\mathrm{OR}=1.48,95 \% \mathrm{CI}=1.22$,
$1.79)$ than in medicine $(\mathrm{OR}=1.35,95 \% \mathrm{CI}=1.22,1.49)$. More students from higher social class backgrounds were observed in medicine than in dentistry amongst the black $(\mathrm{OR}=1.55,95 \%$ $\mathrm{CI}=0.59,4.00)$, Indian $(\mathrm{OR}=2.04,95 \% \mathrm{CI}=1.58,2.62)$ and white $(\mathrm{OR}=1.44,95 \% \mathrm{CI}=1.26,1.64)$ groups.

\section{Conclusions}

Significant inter-ethnic differences are observed in the social background of students entering medicine and dentistry. Dentistry accepted a greater proportion of students from lower social class backgrounds and from black and minority ethnic groups.

\section{In Brief}

- Dentistry, compared with medicine, accepts a greater proportion of students from lower social class backgrounds

- Minority ethnic students who study dentistry, compared with medicine, are more likely to come from a lower social class background

- Monitoring of inequalities of access to medicine and dentistry should not consider minority ethnic groups as a single entity

\section{Comment}

$\mathrm{T}_{\mathrm{t}}$ seems to me a reasonable notion that any profession, particularly a caring one, should reflect by its composition the whole of society and not just a part of it. A profession should, for example not be composed of entrants drawn exclusively from a privileged part of society or from the offspring of existing members of that profession. There are a number of reasons why I believe that this conclusion is correct other than on the grounds of equity and fairness. Firstly, I doubt if any profession will maximise its ability to be adaptive, innovative, and be relevant to those it seeks to serve if it perpetuates a system of real or perceived exclusivity. Additionally, recent controversy over the alleged unfairness of admissions procedures to Oxbridge has shown that there is a public expectation in this regard and we would ignore these issues at our peril.

This paper looks specifically at the social class of ethnic minority entrants to dental and medical schools. The results of this paper, in my view, provide some good news for dentistry, but also some disappointing news. The good news is that we appear to be accepting a higher proportion of students to dentistry compared with medicine from lower social class backgrounds. Our intake from black and other minority ethnic groups also appears to be higher. However, Table 1 and 2 of this paper make bleak reading overall and it is disappointing to see that very few entrants to medicine or dentistry come from a lower social class or are black.

Clearly it will be important to undertake further research in this area and in particular to monitor trends in UCAS information. It will be even more important however for the dental profession collectively and individually to do its best to encourage all of those who are able and motivated enough to consider a career within dentistry. The positive image individual dentists can generate of dentistry with young patients who are considering a career is often crucial. While we can perhaps do little as individuals to influence government policy towards the support funding for students, we can certainly all present dentistry in a positive light as a forward thinking profession needing applicants from all racial and social backgrounds. The BDA is also playing its part by establishing a Transcultural Working Party to examine in detail the barriers that exist or are perceived to exist for entry to the profession from these groups.

\section{John R Drummond \\ Senior Lecturer/Admissions Tutor \\ Dundee Dental school, \\ Dundee University}

